\title{
Strength and Fracture Analysis of Single-Lap Self-Pierce Riveted Joints
}

\author{
X. HE*, Y. Lu, F. LiU, B. Xing, K. ZenG \\ Innovative Manufacturing Research Centre, Faculty of Mechanical and Electrical Engineering, \\ Kunming University of Science and Technology, Kunming, 650500, P.R. China
}

\begin{abstract}
Due to the increased use of lightweight sheet materials, there has been a significant increase in the use of self-pierce riveting. This paper deals with the strength and fracture mechanism of single-lap self-pierce riveted joints. The online window technique was introduced in the single-lap self-pierce riveting processes for evaluating the quality of joints. Signals obtained from sensors were amplified and transferred to the data acquisition system which measures, processes and saves the signals. Monotonic tensile tests were carried out to measure the ultimate tensile strengths for the single-lap self-pierce riveted joints. For investigating the fracture mechanism of the singlelap self-pierce riveted joints, the electrolytic polishing and anode film coating were used for dealing with the cross-section. The differential interference contrast method was used for observing the micro-structure of the crosssection of the joints. The distribution of the hardness in the cross-section of the single-lap self-pierce riveted joints was also studied. The normal hypothesis tests were performed to examine the rationality of the test data.
\end{abstract}

DOI: $10.12693 /$ APhysPolA.127.1424

PACS: 46.70.-p

\section{Introduction}

As a result of the trend towards lightweight construction in manufacturing, some relative new joining techniques are widely used in different industrial fields in recent years [1-4]. Self-pierce riveting (SPR) has also been developed rapidly into a new branch of mechanical joining techniques. There have been a number of published results on the static and fatigue properties of the SPR joints in the past few years. Wood et al. [5] investigated the performance of self-piercing riveted joints in aluminium sheet (A5754) at typical automotive crash speeds. A finite element (FE) model of the fixture and test measurement system was developed to ensure a near optimal design. Durandet et al. [6] studied the laserassisted SPR (LSPR) of AZ31 magnesium alloy strips. A simple but effective thermal analysis of LSPR was presented that enabled both the absorption of the laser radiation and heat transfer between plies to be determined. Mucha and Witkowski [7] analyzed the shearing strength of double joints made of various joining techniques. Porcaro et al. generated an accurate 3D numerical model for the coach peel self-pierce riveted (CPSPR) joint, subjected to various loading conditions [8]. An algorithm was generated in order to transfer all the information from the $2 \mathrm{D}$ numerical model of the riveting process to the $3 \mathrm{D}$ numerical model of the joint.

In present study, the strength and fracture mechanism of single-lap self-pierce riveted joints were investigated. The online window technique was introduced in the single-lap self-pierce riveting processes for evaluating

* corresponding author; e-mail: hhxxcc@yahoo.co.uk the quality of the joints. Monotonic tensile tests were carried out to measure the ultimate tensile strengths of the joints. For investigating the fracture mechanism of the single-lap self-pierce riveted joints, the electrolytic polishing and anode film coating were used for dealing with the cross-section. The differential interference contrast method was used for observing the microstructure of the cross-section of the joints. The distribution of the hardness in the cross-section of the single-lap self-pierce riveted joints was also studied. The normal hypothesis tests were performed to examine the rationality of the test data.

\section{Configuration, material properties of SPR joints}

As shown in Fig. 1, the SPR joint comprises an upper sheet, lower sheet and rivet. The tested sheet materials were 5754 aluminum alloy plates of dimensions $110 \mathrm{~mm}$ length, $20 \mathrm{~mm}$ width, $2 \mathrm{~mm}$ thickness, which were joined together in the central part of lap section with one rivet. The rivet is made of high strength steel and is of dimensions $5.5 \mathrm{~mm}$ long, $5 \mathrm{~mm}$ diameter. The mechanical properties of the materials are shown in Table.

Material parameters.

TABLE

\begin{tabular}{c|c|c|c|c|c}
\hline \hline Material & $\begin{array}{c}\text { Young's } \\
\text { modulus } \\
{[\mathrm{MPa}]}\end{array}$ & $\begin{array}{c}\text { Poisson's } \\
\text { ratio }\end{array}$ & $\begin{array}{c}\text { Yield } \\
\text { stress } \\
{[\mathrm{MPa}]}\end{array}$ & $\begin{array}{c}\text { Ultimate } \\
\text { stress } \\
{[\mathrm{MPa}]}\end{array}$ & $\begin{array}{c}\text { Elongation } \\
\text { at failure } \\
{[\%]}\end{array}$ \\
\hline Rivet & 189000 & 0.30 & 1520.0 & 1720.0 & 22 \\
\hline Al5754 & 70300 & 0.33 & 114.0 & 250.0 & 24
\end{tabular}

\section{Single-lap SPR process online monitoring}

With a built in window monitoring system, SPR processes were carried out by a RIVSET MTF SPR machine. 


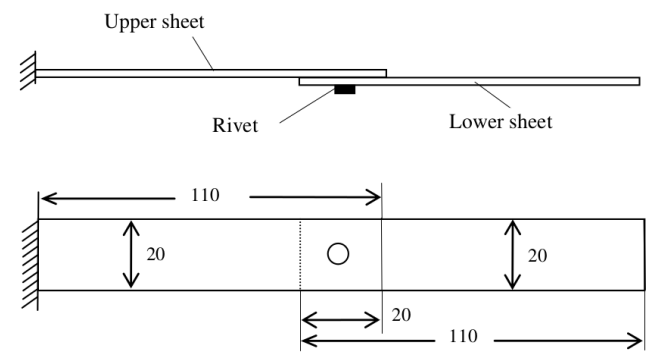

Fig. 1. A single lap SPR joint.

The process window monitoring of SPR joint is carried out by measuring actual SPR setting force through a force sensor and punch travel through a position sensor. The SPR setting force reflects the deformation force on the sheet materials and the punch travel indicated the geometric change of the sheets during SPR process. Signals obtained from sensors are amplified and transferred to the data acquisition system which measures, processes and saves the signals. A computer is used to save the measured data and generate the force-travel curves. All SPR joints were made with constant pre-clamp $(5 \mathrm{kN})$ and setting $(45 \mathrm{kN})$ load.

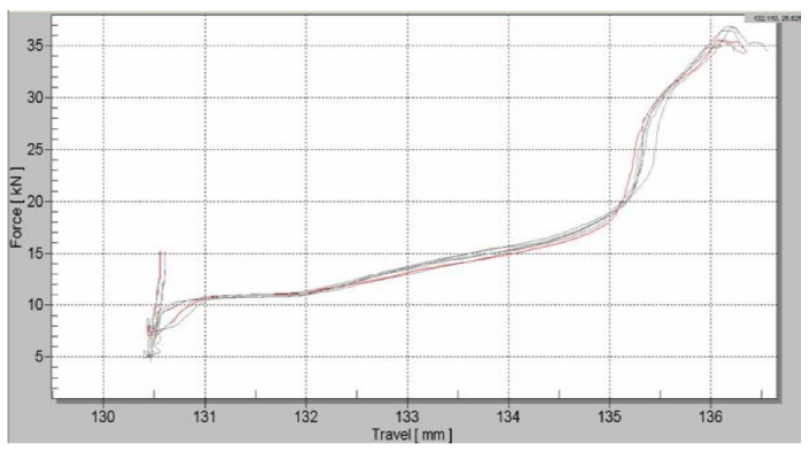

Fig. 2. Force-travel curves of SPR joints.

Before the monitoring process, a reference force-travel curve must be established under the standard work conditions which were based on a range of experiments. The SPR joint could be supposed to be of good quality under these conditions. It is obvious that under the same work conditions, the monitoring force-travel curves should be very close to the reference one and nearly the same. The corresponding SPR joints would have similar good quality. Figure 2 and 3 a show the force-travel curves and SPR joints separately.

\section{Tensile tests}

A servo-hydraulic testing machine with hydraulic grips was used for conducting the tensile tests of SPR joints. All tests were performed by using displacement control. The upper end of the joints was fixed and a quasi-static downward displacement was applied to the lower end. The displacement rate of $5 \mathrm{~mm} / \mathrm{min}$ was applied for all tests. Continuous records of the applied displacementload curves were obtained during each test. Figure 3b (a) SPR joints

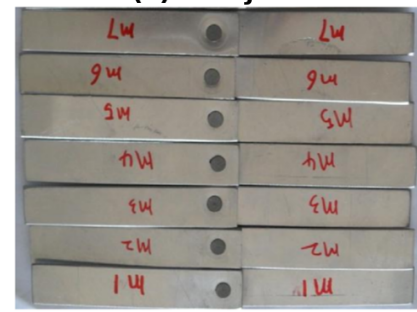

ᄀ3

(b) Tensile process

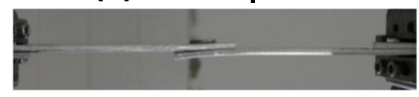

ת

(c) Failed SPR joints

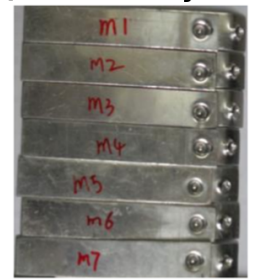

Fig. 3. Tensile tests of the SPR joints.

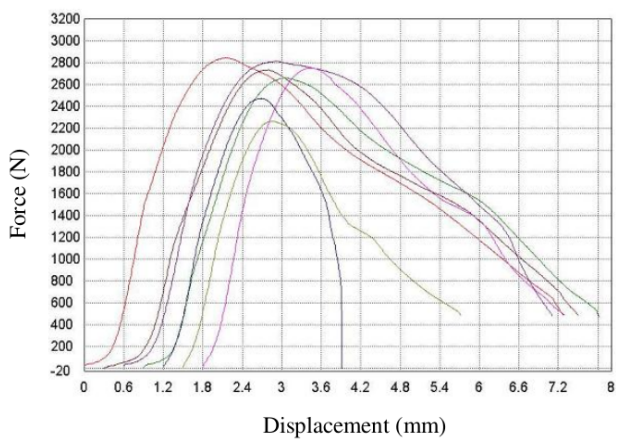

Fig. 4. Force-displacement curves of SPR joints.

shows the monotonic tensile process. It is clear that joint rotation occurs during tensile tests.

\section{Experimental results}

Figure 3c shows failed SPR joints. It can be seen from Fig. $3 c$ that the failure mode was plate failure forming at the contact location between the rivet bottom and the lower sheet. In the tests, plastic deformation around contact location developed to such a large level that the rivet was pulled out from the lower sheet.

Figure 4 shows the force-displacement curves of SPR joints. To examine the rationality of the test data, the normal hypothesis tests were performed using MATLAB 7.0. The results show that the maximum tensile strengths of SPR joints follow normal distributions. The mean values $(\mu)$ and standard deviations $(\sigma)$ have the following numerical values: $\mu=2646.4 \mathrm{~N}, \sigma=209.13 \mathrm{~N}$. All test data fitting the region estimated by the degree of confidence of $95 \%$ and the confidence interval is [2353.4- 


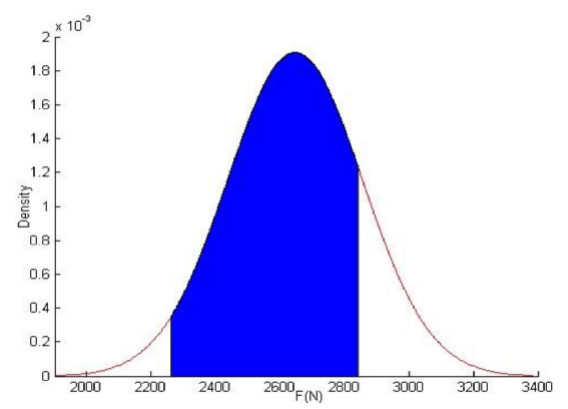

Fig. 5. Maximum tensile strengths normal probability density distributions of the SPR joints.

2939.5]. The maximum tensile strengths normal probability density distributions of the SPR joints are showed in Fig. 5.

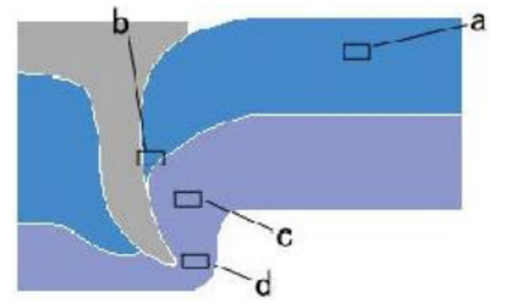

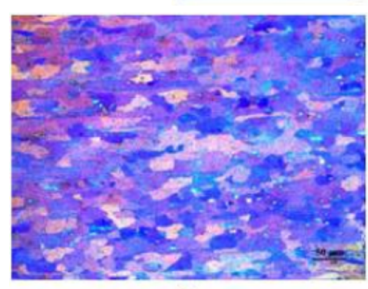

a

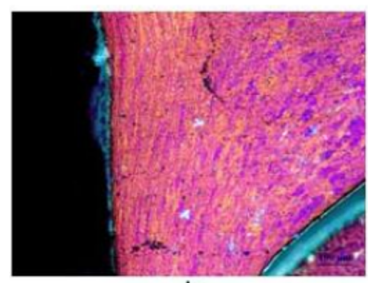

b

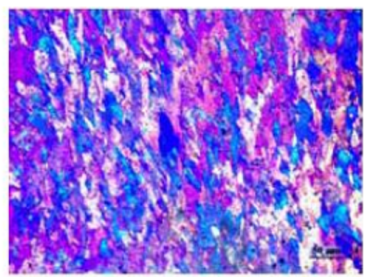

C

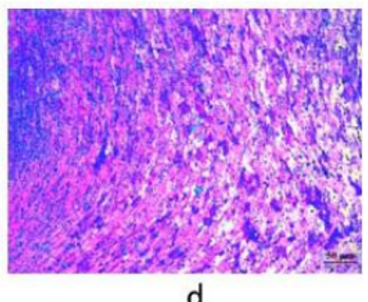

d

Fig. 6. Microstructure variations on the cross-section of SPR specimen in: (a) un-deformed zone; (c) mechanically affected zone; (b) and (d) rivet-sheet contacted zone.

\section{Fracture mechanism}

For investigating the fracture mechanism of the SPR joints, a SPR joint specimen was cut from the center-line of the rivet perpendicular to the length of the specimen. As is well known, it is difficult to display the grains of aluminum alloy by normal chemistry etching. The electrolytic polishing and anode film coating were used for dealing with the cross-section, then the differential interference contrast (DIC) method was used for observing the micro-structure of the cross-section of the SPR joint. Figure 6 shows a variation in grain size and shape from un-deformed zone, to mechanically af-

fected zone, then to rivet-sheet contacted zone. The average grain size ranges from $45 \mu \mathrm{m}$ at un-deformed zone (Fig. 6a) to $37 \mu \mathrm{m}$ at mechanically affected zone (Fig. 6c) then to $25 \mu \mathrm{m}$ at rivet-sheet contacted zone (Fig. 6b, 6d). The grain shape changes from equiaxed grain to streaky grain. Alternatively the distribution of the hardness in the cross-section has also been studied. Similarly the average hardness ranges from $73 \mathrm{HV}$ at un-deformed zone to $85 \mathrm{HV}$ at mechanically affected zone then to $102 \mathrm{HV}$ at rivet-sheet contacted zone. It implies that the material around the rivet was remarkably work hardened due to the plastic deformation during the SPR process.

It can be seen from Fig. 6 that some cracks have occurred in upper sheet at the interfaces between the rivet and sheet or the two sheets (Fig. 6b). That could be the reason why all of the failures occur in the upper sheet of the SPR joints. It was confirmed that the crack site in the cross-section is in accord with fracture site in experimental tests.

\section{Conclusions}

SPR is a new high-speed mechanical fastening technique which is suitable for point joining advanced lightweight sheet materials. The ultimate tensile strength and fracture mechanism of the single-lap SPR joints was investigated in this study. The online window technique was introduced in the single-lap SPR processes for evaluating the quality of the joints. Signals obtained from sensors were amplified and transferred to the data acquisition system which measures, processes and saves the signals. Tensile tests were carried out to measure the ultimate tensile strengths for the joints. Deformation and failure of the single-lap SPR joints under monotonic tensile loading were studied. The electrolytic polishing and anode film coating were used for dealing with the crosssection, the differential interference contrast method was used for observing the microstructure of the cross-section of the joints. The normal hypothesis tests were performed to examine the rationality of the test data.

\section{Acknowledgments}

This study is partially supported by National Natural Science Foundation of China (Grant No. 50965009).

\section{References}

[1] X. He, F. Gu, A. Ball, Progress Mater. Sci. 65, 1 (2014).

[2] X. He, Mater. Manuf. Process. 27, 1354 (2012).

[3] X. He, Int. J. Adhes. Adhes. 53, 34 (2014).

[4] X. He, L. Zhaoa, H. Yanga, B. Xinga, Y. Wanga, C. Denga, F. Gub, A. Ball, Comput. Mater. Sci. 94, 58 (2014).

[5] P.K.C. Wood, C.A. Schley, M.A. Williams, A. Rusinek, Mater. Des. 32, 2246 (2011).

[6] Y. Durandet, R. Deam, A. Beer, W. Song, S. Blacket, Mater. Des. 31, S13 (2010).

[7] J. Mucha, W. Witkowski, Thin-Wall. Struct. 66, 39 (2013).

[8] R. Porcaro, A.G. Hanssen, M. Langseth, A. Aalberg, Int. J. Solid. Struct. 43, 5110 (2006). 